\title{
NMR Measurement of Identical Polymer Samples by Round Robin Method V. Determination of Degree of Polymerization for Isotactic Poly(methyl methacrylate) Having a $t$-Butyl End Group
}

\author{
Koichi Hatada ${ }^{\dagger}$ Tatsuki Kitayama, Yoshio TerawaKi, Hisaya Sato, ${ }^{*}$ Fumitaka HoriI, ${ }^{* *}$ \\ and Members of Research Group on NMR, SPSJ"† \\ Department of Chemistry, Graduate School of Engineering Science, Osaka University \\ Toyonaka, Osaka 560-8531, Japan \\ ${ }^{*}$ Department of Material Systems Engineering, Faculty of Engineering, Tokyo University of Agriculture \\ and Technology, Koganei, Tokyo 184-0012, Japan \\ ** Institute for Chemical Research, Kyoto University, Uji, Kyoto 611-0011, Japan
}

(Received January 27, 2003; Accepted February 21, 2003)

\begin{abstract}
Research Group on NMR, The Society of Polymer Science, Japan, has continued assessments of the reliability of NMR measurements of polymers. In the present study, ${ }^{1} \mathrm{H}$ and ${ }^{13} \mathrm{C}$ NMR data for isotactic poly(methyl methacrylate) (it-PMMA) having a $t$-butyl end group were collected on 27 NMR spectrometers by a round-robin method, to survey the accuracy of NMR spectroscopic determination of degree of polymerization $(D P)$ of the polymer by the end group analysis as well as other basic NMR parameters such as chemical shift and spectral resolution. Five samples of $i t$-PMMAs whose $D P$ 's range from 53 to 5200 were prepared with $t$-BuMgBr in toluene. ${ }^{1} \mathrm{H}$ and ${ }^{13} \mathrm{C}$ NMR spectra were measured in nitrobenzene- $d_{5}$ at $110^{\circ} \mathrm{C}$. The standard deviations $(\sigma)$ for chemical shift measurements of ${ }^{1} \mathrm{H}$ and ${ }^{13} \mathrm{C}$ NMR signals were $0.001-0.004 \mathrm{ppm}$ and $0.04-0.18 \mathrm{ppm}$, respectively. A singlet signal due to $t$-butyl group at initiating chain end of the it-PMMA is separately observed from the signals due to the monomeric units in ${ }^{1} \mathrm{H}$ NMR spectra measured in nitrobenzene- $d_{5}$. Thus $D P$ of the polymer can be determined by the equation of $D P=3 \times\left[\mathrm{OCH}_{3}\right] /\left[t-\mathrm{C}_{4} \mathrm{H}_{9}\right]$. The value of $\sigma$ for $D P$ determination by ${ }^{1} \mathrm{H}$ NMR increased as $D P$ increased (6.4-23.4\%). However, the averaged values of $D P$ agreed well with those determined by SEC. ${ }^{13} \mathrm{C}$ NMR analysis of $D P$ was possible for the $i t$-PMMA with $D P$ up to $c a$. 250. The values agreed with those determined by ${ }^{1} \mathrm{H}$ NMR spectroscopy. ${ }^{1} \mathrm{H}$ NMR determination of $D P$ by 5 runs using single spectrometers (100 and $500 \mathrm{MHz}$ ) gave much better reproducibility; $\sigma 3.9-9.2 \%$ and $0.7-3.4 \%$ for the measurements with 100 and $500 \mathrm{MHz}$ instruments, respectively.

KEY WORDS $\quad{ }^{1} \mathrm{H}$ NMR $/{ }^{13} \mathrm{C}$ NMR / Poly(methyl methacrylate) / Round Robin Method / End Group Analysis / Reliability / Chemical Shift / Resolution / DP / Precision / Accuracy /
\end{abstract}

Research group on NMR, the Society of Polymer Science Japan (SPSJ), has made assessments on the reliability of NMR measurements of polymers. In a series of this cooperative research work the reliability of chemical shift, signal intensity, spin-lattice relaxation time, nuclear Overhauser enhancement factor, and quantitative analysis of copolymer composition have been investigated for ${ }^{1} \mathrm{H}$ and ${ }^{13} \mathrm{C}$ NMR measurements of polymer samples and the results have been reported in this journal. ${ }^{1-4}$

In the present work the reliability of degree of polymerization $(D P)$ determined by end-group analy- sis was studied by round robin method for poly(methyl methacrylate) (PMMA). The Committee on Molecular Weight and Molecular Weight Distribution of the Society of Polymer Science Japan reported previously the results of measurements of molecular weight and its distribution by round robin method. ${ }^{5}$ The present study is the NMR version of round robin test of $D P$. The PMMAs of several $D P$ 's were prepared through the living polymerization with $t-\mathrm{C}_{4} \mathrm{H}_{9} \mathrm{MgBr}$ in toluene at $-60{ }^{\circ} \mathrm{C}$ and found to contain a $t-\mathrm{C}_{4} \mathrm{H}_{9}$ group at the initiating chain end of the macromolecule. ${ }^{6}$ The ${ }^{1} \mathrm{H}$ and ${ }^{13} \mathrm{C}$ NMR data were collected from $27(100-500 \mathrm{MHz})$ and

\footnotetext{
${ }^{\dagger}$ Present address: Fukui University of Technology, Department of Applied Physics and Chemistry, 3-6-1 Gakuen, Fukui-shi, Fukui 9108505, Japan.

${ }^{\dagger \dagger}$ T. Araki (Denki Kagaku Kogyo Kabushiki Kaisha), R. Chujo (The Nishi-Tokyo-University), M. Hashimoto (Nitto Technical Information Center Co., Ltd.) M. Ikeyama (Japan Synthetic Rubber Co.), A. Isokawa (Daicel Chemical Industries, Ltd.), M. Kanda (Denki Kagaku Kogyo Kabushiki Kaisha), H. Kurosu (Tokyo Institute of Technology), K. Lee (Osaka University), A. Matsumoto (Daicel Chemical Industries, Ltd.), K. Matsumura (Unitika Research Labo.), A. Mizuno (San Analysis \& Consulting Service), T. Mori (Mitsubishi Petrochemical Co.), H. Ninomiya (Ube Scientific Analysis Laboratory, Inc.), H. Saito (Himeji Institute of Technology), S. Sangen (Himeji Institute of Technology), M, Shimoda (Nippon Zeon Co., Ltd.), K. Sueoka (Tosoh Corporation), and Y. Takai (Osaka University).
} 
Table I. it-PMMA samples prepared in toluene with $t-\mathrm{C}_{4} \mathrm{H}_{9} \mathrm{MgBr}$ at $-60{ }^{\circ} \mathrm{C}$

\begin{tabular}{|c|c|c|c|c|c|}
\hline \multirow{2}{*}{ Sample } & \multirow{2}{*}{$D P$} & \multirow{2}{*}{$\bar{M}_{\mathrm{w}} / \bar{M}_{\mathrm{n}}^{\mathrm{a}}$} & \multicolumn{3}{|c|}{ Tacticity $(\%)^{\mathrm{b}}$} \\
\hline & & & $\mathrm{mm}$ & $m r$ & $r r$ \\
\hline 1 & 53.4 & 1.095 & 96.8 & 3.0 & 0.2 \\
\hline 2 & 120.6 & 1.118 & 96.7 & 3.1 & 0.2 \\
\hline 3 & 256 & 1.125 & 97.5 & 2.4 & 0.1 \\
\hline 4 & 977 & 1.379 & 95.3 & 3.6 & 1.1 \\
\hline 5 & 5200 & 1.41 & 94.0 & 3.0 & 3.0 \\
\hline
\end{tabular}

${ }^{\mathrm{a}}$ Determined by SEC. ${ }^{\mathrm{b}}$ Determined by ${ }^{1} \mathrm{H}$ NMR.

$23(50-125 \mathrm{MHz})$ spectrometers, respectively. The $D P$ values were determined from the ${ }^{1} \mathrm{H}$ NMR signal intensities of $t-\mathrm{C}_{4} \mathrm{H}_{9}-$ and $-\mathrm{OCH}_{3}$ groups in the polymer and the obtained values were compared with those measured by size exclusion chromatography (SEC) for the accuracy. ${ }^{\dagger \dagger}$ The precisions of $D P$ determination by round robin method for ${ }^{1} \mathrm{H}$ NMR were $6.4-23.4 \%$ depending on the magnitude of $D P$; the values increased with increasing $D P$ values. The precision of determination by a single $500 \mathrm{MHz}$ spectrometer was $0.7-3.4 \%$ which is much better than that by round robin method. ${ }^{13} \mathrm{C}$ NMR analysis of the $D P$ was also possible for the it-PMMA with $D P$ up to about 250 although the fluctuation of the data is rather large.

\section{EXPERIMENTAL}

Five samples of isotactic (it-) PMMAs used in the measurements were prepared by the living polymerizations with $t-\mathrm{C}_{4} \mathrm{H}_{9} \mathrm{MgBr}$ in toluene at $-60{ }^{\circ} \mathrm{C},{ }^{6}$ and tacticity, $D P$ and $\bar{M}_{\mathrm{w}} / \bar{M}_{\mathrm{n}}$ values of the samples are listed in Table I.

SEC chromatography of the PMMAs was performed on a JASCO FLC-A10 chromatograph equipped with a Shodex A-80 M SEC column $(50 \mathrm{~cm} \times 2)$ using tetrahydrofuran as an eluent. RI and LALLS detectors were used. The molecular weight calibration was made using standard polystyrenes.

The PMMA samples were dissolved in nitrobenzene$d_{5}$. The solutions were filtered under dry nitrogen to remove insoluble materials. The filtered solution of each sample was degassed, and sealed under nitrogen in $5 \mathrm{~mm}$ NMR sample tubes. The concentrations of the solutions were $10 \mathrm{wt} \mathrm{vol}^{-1} \%$ for samples $1-4$ and $5 \mathrm{wt} \mathrm{vol}-1 \%$ for sample 5 . Five sets of five sample tubes were circulated among collaborating test sites. The research work was carried out by several non-members as well as SPSJ members.

The number of spectrometers used was 27 for ${ }^{1} \mathrm{H}$ NMR measurements $(100-500 \mathrm{MHz})$ and 23 for ${ }^{13} \mathrm{C}$
Table II. Conditions for the measurements of NMR spectra

\begin{tabular}{lcc}
\hline & ${ }^{1} \mathrm{H}$ & ${ }^{13} \mathrm{C}$ \\
\hline Solvent & $\mathrm{NB}-d_{5}{ }^{\mathrm{a}}$ & $\mathrm{NB}-d_{5}{ }^{\mathrm{a}}$ \\
Conc. wt vol ${ }^{-1} \%^{\mathrm{b}}$ & 10,5 & 10 \\
Temp. $\left({ }^{\circ} \mathrm{C}\right)$ & 110 & 110 \\
Obs.range(ppm) & 15 & 250 \\
Pulse width $\left({ }^{\circ}\right)$ & 45 & 45 \\
Pulse repetn. $(\mathrm{s})$ & 10 & 10 \\
Number of scans & $32-5700$ & $3000-32000$ \\
Decoupling & - & $\mathrm{NNE}^{\mathrm{c}}$ \\
\hline
\end{tabular}

${ }^{\mathrm{a}}$ Nitrobenzene- $d_{5}$. ${ }^{\mathrm{b}}$ The concentration of solutions were $10 \mathrm{wt} \mathrm{vol}^{-1} \%$ for the samples $1-4$ and $5 \mathrm{wt} \mathrm{vol}^{-1} \%$ for sample 5 . ${ }^{\mathrm{c}}$ Gated decoupling without NOE.
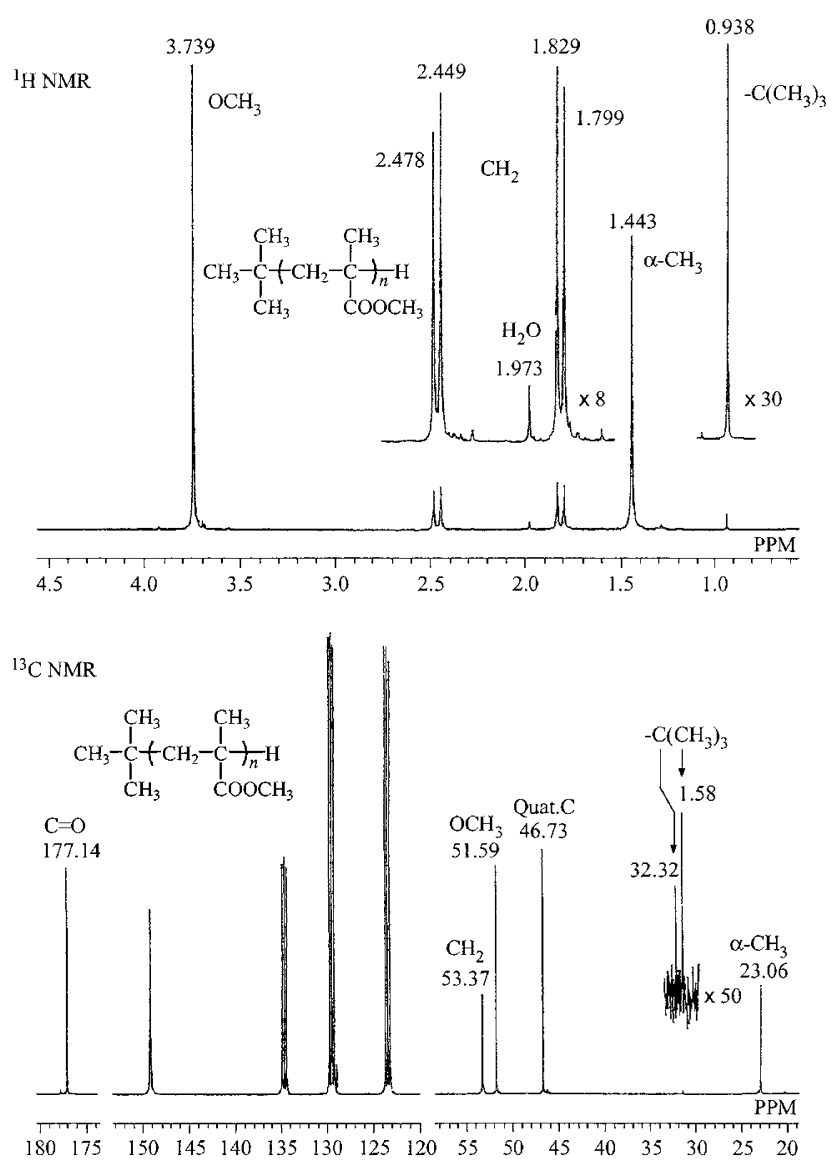

Figure 1. $500 \mathrm{MHz}{ }^{1} \mathrm{H}$ and $100 \mathrm{MHz}{ }^{13} \mathrm{C}$ NMR spectra of itPMMA (Sample 1 in Table I) in nitrobenzene- $d_{5}$ at $110^{\circ} \mathrm{C}$. The chemical shift values indicated in the figure are the averaged ones obtained from the determinations by round robin method.

NMR measurements $(50-125 \mathrm{MHz})$. The conditions for ${ }^{1} \mathrm{H}$ and ${ }^{13} \mathrm{C}$ NMR measurements are summarized in Table II. Typical ${ }^{1} \mathrm{H}$ and ${ }^{13} \mathrm{C}$ NMR spectra of the sample are shown in Figure 1. The peak assignments are depicted in the figure. ${ }^{1} \mathrm{H}$ and ${ }^{13} \mathrm{C}$ chemical shifts referred to the signals due to the residual meta protons $(8.091 \mathrm{ppm})$ and ipso carbon $(149.10 \mathrm{ppm})$ of nitrobenzene- $d_{5}$, respectively and were converted into

\footnotetext{
${ }^{\dagger \dagger}$ This strategy is an extension of the idea appearing in the paper of Demarquay et al., ${ }^{7}$ in which DP of PVC has been determined by comparison of the NMR intensity for the polymer main chain with that for the $t-\mathrm{C}_{4} \mathrm{H}_{9}$ group from the initiator, $t$ - $\mathrm{C}_{4} \mathrm{H}_{9} \mathrm{MgCl}$.
} 
Table III. Line width (ppm) $)^{a}$ of $\mathrm{OCH}_{3}$ proton signal in the ${ }^{1} \mathrm{H}$ NMR spectra of $i t$-PMMAs

\begin{tabular}{cclllll}
\hline $\begin{array}{c}\text { Freq. } \\
\text { (MHz) }\end{array}$ & $\mathrm{n}^{\mathrm{b}}$ & \multicolumn{5}{c}{ Sample $^{\mathrm{c}}$} \\
\cline { 4 - 7 } & & \multicolumn{1}{c}{1} & \multicolumn{1}{c}{2} & \multicolumn{1}{c}{3} & \multicolumn{1}{c}{4} \\
\hline 100 & 2 & $0.2071(1.3)$ & $0.2132(3.4)$ & $0.2065(4.2)$ & $0.2543(2.4)$ & $0.2522(5.7)$ \\
200 & 1 & $0.1258(-)$ & $0.1456(-)$ & $0.1429(-)$ & $0.1301(-)$ & $0.2568(-)$ \\
270 & 9 & $0.1172(14.6)$ & $0.1215(15.6)$ & $0.1169(15.6)$ & $0.1302(21.1)$ & $0.1831(17.8)$ \\
300 & 1 & $0.0977(-)$ & $0.0998(-)$ & $0.0951(-)$ & $0.1035(-)$ & $0.1763(-)$ \\
360 & 1 & $0.0907(-)$ & $0.0933(-)$ & $0.0920(-)$ & $0.1040(-)$ & $0.1600(-)$ \\
400 & 7 & $0.0962(16.7)$ & $0.0959(7.9)$ & $0.0958(6.4)$ & $0.0911(17.7)$ & $0.1616(17.9)$ \\
500 & 6 & $0.1004(9.6)$ & $0.0981(6.9)$ & $0.0885(12.7)$ & $0.0960(17.2)$ & $0.1512(15.3)$ \\
\hline
\end{tabular}

${ }^{\mathrm{a}}$ The line width at the level of ${ }^{13} \mathrm{C}$-satelite. ${ }^{\mathrm{b}}$ Number of spectrometers used. ${ }^{\mathrm{c}}$ Figures in parentheses represent the precision $(\%)$.

TMS scales.

The precision of measurements is represented by the percent ratio of the standard deviation to the number averaged value of the determinations.

\section{RESULTS AND DISCUSSION}

\section{Reliability of Chemical Shift Measurement and Spectral Resolution}

Averaged values of ${ }^{1} \mathrm{H}$ and ${ }^{13} \mathrm{C}$ NMR chemical shifts of $i t$-PMMA (Sample 1) are indicated in Figure 1. The precisions of chemical shift measurements for this itPMMA sample were found to be $\pm 0.001-0.004 \mathrm{ppm}$ for ${ }^{1} \mathrm{H}$ NMR and $\pm 0.04-0.18$ ppm for ${ }^{13} \mathrm{C}$ NMR. The both values are smaller than the corresponding values obtained for the atactic PMMA in the round robin experiments in $1987^{1}\left( \pm 0.0036-0.0071 \mathrm{ppm}\right.$ for ${ }^{1} \mathrm{H}$ NMR and $\pm 0.054-0.307 \mathrm{ppm}$ for ${ }^{13} \mathrm{C}$ NMR). This may be due to the facts that it-PMMA shows sharp and wellseparated peaks as compared with atactic one and that the performance and stability of NMR instruments have been improved recently.

In order to evaluate the spectral resolutions of ${ }^{1} \mathrm{H}$ NMR spectra, the line widths for $\mathrm{OCH}_{3}$ proton resonances at the ${ }^{13} \mathrm{C}$-satelite level were measured. The results are shown in Table III. The line widths in ppm decreased generally with increasing frequency of measurements regardless of the samples. Since the isotacticities of the PMMAs are very high and accordingly the signals consist of almost single component, the results obtained here indicate that the spectral resolutions are enhanced with increasing frequency of measurement. Sample 5 having a $D P$ of 5200 showed a large spectral width as compared with other four samples, which may be due to the high viscosity of the solution. Relatively large values of precision may be partly due to the fact that the maximum value of spectral resolution is difficult to attain for the solution of polymer sample.

Spectral resolution should be enhanced at higher temperatures. $500 \mathrm{MHz}{ }^{1} \mathrm{H}$ NMR spectra of sam-



Figure 2. Line widths of $500 \mathrm{MHz}{ }^{1} \mathrm{H}$ NMR spectrum of sample 1 at various temperatures.

ple 1 were measured at various temperatures (Figure 2). With an increase in temperature the line widths of main-chain $\mathrm{CH}_{2}$ and $\alpha$ - $\mathrm{CH}_{3}$ proton signals decrease greatly up to $80^{\circ} \mathrm{C}$ and then gradually above $80^{\circ} \mathrm{C}$ while those of $t-\mathrm{C}_{4} \mathrm{H}_{9}$ proton signal hardly change with temperature. The plots for $\mathrm{OCH}_{3}$ signal are in-between. The results indicate that the segmental mobility of the back bone chain is restricted at lower temperatures as compared with the substituent group apart from the main chain such as $-\mathrm{OCH}_{3}$ group and with the substituent at the chain end. The appropriate temperature of measurement should be above $80^{\circ} \mathrm{C}$.

\section{Reliability of Temperature Set-Up in the Spectrometer Used}

It is important for understanding some of the NMR parameters such as temperature-dependent chemical 


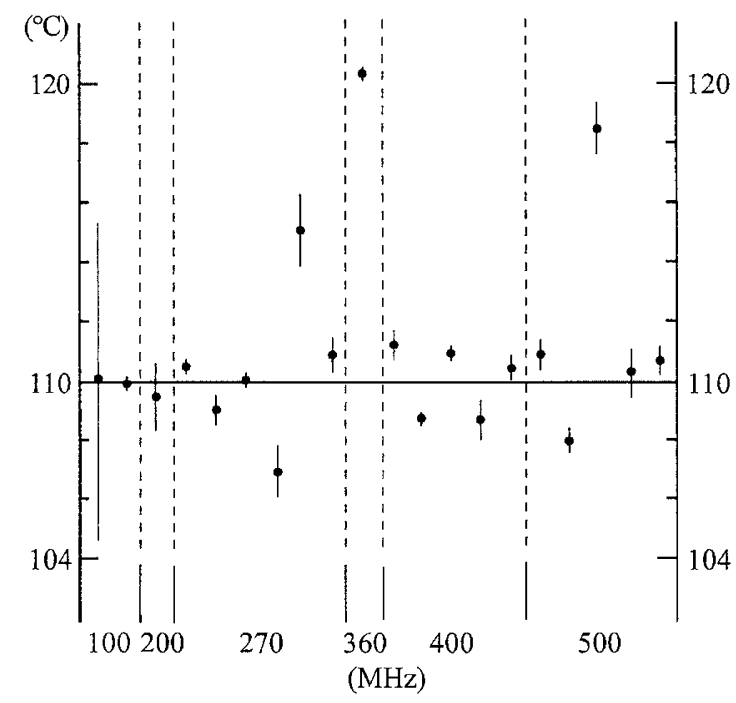

Figure 3. Accuracy and precision of the temperature of measurement of NMR spectrum. The vertical lines transfixing the circles represent the fluctuation of the temperature of sample solutions.

shift and relaxation times to note whether or not the real temperature of the sample solution meets the temperature set on the instrument used. In order to check this point for the data collected by round robin method, the chemical shifts of a small amount of water contained in the sample solutions were investigated. The relationship between the ${ }^{1} \mathrm{H}$ chemical shift of the water and the temperature of the sample solution was determined for the five individual test samples from the ${ }^{1} \mathrm{H}$ NMR measurement at one of the test sites (Hatada's laboratory) using a $100 \mathrm{MHz}$ NMR spectrometer (JNM-FX100). Using the calibration curve thus obtained for each sample, the temperature of the sample solution at each ${ }^{1} \mathrm{H}$ NMR measurement was evaluated from the chemical shift of the water. The range and averaged values of the temperature for five sample solutions were determined for each spectrometer and are shown in Figure 3. The fluctuation of the temperatures for the measurements of five sample solutions installed in a given spectrometer was within $\pm 0.8{ }^{\circ} \mathrm{C}$ with a few exceptions; the range of the fluctuation is slightly but meaningfully smaller than that $\left( \pm 1.0^{\circ} \mathrm{C}\right)$ obtained in the previous work in $1995 .{ }^{4}$ The averaged values of the solution temperatures for respective instruments were in the range from 106.2 to $111.3^{\circ} \mathrm{C}$ with three exceptions. The averaged value for all the instruments $\left(110.4^{\circ} \mathrm{C}\right)$ was almost the same as the temperature set on the instrument; $110^{\circ} \mathrm{C}$.

The temperature of the sample solution of the instrument operated at $360 \mathrm{MHz}$ was higher than the set up temperature by over $10^{\circ} \mathrm{C}$. This may be the reason why the spectrum showed sharp signals as compared with those obtained by other spectrometers (see Figure 3 and Table III).
Table IV. ${ }^{1} \mathrm{H}$ and ${ }^{13} \mathrm{C}$ spin-lattice relaxation time $T_{1}$ (s) of it-PMMA samples measured at 500 and $125 \mathrm{MHz}$, respectively at $110^{\circ} \mathrm{C}$

\begin{tabular}{lcccccc}
\hline \multirow{2}{*}{ Hydrogen } & \begin{tabular}{c} 
Chem. \\
shift \\
\cline { 4 - 7 }
\end{tabular} & \multicolumn{5}{c}{ Sample } \\
\cline { 5 - 7 } & 3.74 & 1.38 & 1.35 & 1.36 & 1.36 & 1.32 \\
\hline $\mathrm{OCH}_{3}$ & 2.48 & 0.376 & 0.363 & 0.361 & 0.364 & 0.360 \\
$\mathrm{CH}_{2}$ & 2.45 & 0.371 & 0.364 & 0.360 & 0.364 & 0.361 \\
$\mathrm{CH}_{2}$ & 1.83 & 0.335 & 0.321 & 0.323 & 0.327 & 0.321 \\
$\mathrm{CH}_{2}$ & 1.80 & 0.330 & 0.321 & 0.322 & 0.326 & 0.322 \\
$\mathrm{CH}_{2}$ & 1.44 & 0.424 & 0.407 & 0.399 & 0.408 & 0.408 \\
$\alpha-\mathrm{CH}_{3}$ & 0.94 & 1.30 & 1.24 & 1.30 & 1.24 & 1.23 \\
$t-\mathrm{C}_{4} \mathrm{H}_{9}$ & & & & & & \\
\hline
\end{tabular}

\begin{tabular}{lclllll}
\hline \multirow{2}{*}{ Carbon } & $\begin{array}{c}\text { Chem. } \\
\text { shift } \\
(\mathrm{ppm})\end{array}$ & \multicolumn{6}{c}{1} & \multicolumn{5}{c}{ Sample } \\
\cline { 3 - 7 } & 177.1 & 2.19 & 2.42 & \multicolumn{1}{c}{3.30} & \multicolumn{1}{c}{4} & 5 \\
\hline $\mathrm{CO}$ & 53.4 & 0.255 & 0.252 & 0.244 & 0.246 & 2.07 \\
$\mathrm{CH}_{2}$ & 52.0 & 1.57 & 1.56 & 1.55 & 1.46 & 1.57 \\
$\mathrm{OCH}_{3}$ & 52.046 \\
Quat.C & 46.7 & 3.65 & 3.62 & 3.76 & 3.77 & 3.62 \\
$t-\mathrm{C}_{4} \mathrm{H}_{9}$ & 31.6 & 1.44 & 1.41 & $\sim 1.6$ & - & - \\
$\alpha-\mathrm{CH}_{3}$ & 23.1 & 0.465 & 0.473 & 0.462 & 0.456 & 0.461 \\
\hline
\end{tabular}

\section{Determination of DP by ${ }^{1} \mathrm{H}$ and ${ }^{13} \mathrm{C} N M R$ and Their} Reliability

The $D P$ values of the PMMA samples were determined by the intensity ratio of $\mathrm{OCH}_{3}$ proton signal to $t-\mathrm{C}_{4} \mathrm{H}_{9}$ proton one and of $\alpha-\mathrm{CH}_{3}$ carbon signal to $\mathrm{CH}_{3}$ carbon signal of $t-\mathrm{C}_{4} \mathrm{H}_{9}$ group. To obtain accurate signal intensity pulse repetition time must be sufficiently long for the magnetization to relax to an equilibrium state. With a $90^{\circ}$ pulse, pulse repetition time of $5 T_{1}$ allows the magnetization to recover more than $99 \%$ of an equilibrium value. The ${ }^{1} \mathrm{H}$ and ${ }^{13} \mathrm{C}$ spin-lattice relaxation times $\left(T_{1}\right)$ of all the PMMA samples were measured at 500 and $125 \mathrm{MHz}$, respectively at $110^{\circ} \mathrm{C}$ and are shown in Table IV. Most of the $T_{1}$ values decreased slightly in the order from sample 1 to sample 5, probably due to the decreasing segmental mobility with increasing molecular weight. The ${ }^{1} \mathrm{H}$ and ${ }^{13} \mathrm{C} T_{1}$ 's for $\mathrm{OCH}_{3}, \alpha-\mathrm{CH}_{3}$, and $t-\mathrm{C}_{4} \mathrm{H}_{9}$ groups are all less than $2 \mathrm{~s}$ (Table IV). The $T_{1}$ 's except for that of $\mathrm{C}=\mathrm{O}$ group decrease with a decrease in the frequency of measurement. $^{2}$ Accordingly, the pulse repetition time of $10 \mathrm{~s}$ and the pulse width of $45^{\circ}$ used in the measurements are very suitable for quantitative determination.

All the respective determinations of $D P$ measured by ${ }^{1} \mathrm{H}$ NMR are listed in Table V. Although the fluctuation of data seems rather large, the precisions for the samples 1, 2, and $3[D P$ determined by SEC, $D P(\mathrm{SEC})=53.4-256]$ remain within $9 \%$. The values of precision exceed $10 \%$ for samples 4 and $5[D P$ $(\mathrm{SEC})=977-5200]$. The averaged values of $D P$ for all the samples agree well with the $D P$ values obtained by 
Table V. ${ }^{1} \mathrm{H}$ NMR determination of $D P$ of $i$-PMMA sample

\begin{tabular}{|c|c|c|c|c|c|c|c|c|c|c|c|}
\hline \multirow{2}{*}{\multicolumn{2}{|c|}{$\begin{array}{l}\text { Freq. } \\
(\mathrm{MHz})\end{array}$}} & \multicolumn{10}{|c|}{ Sample $^{\mathrm{a}}$} \\
\hline & & \multicolumn{2}{|r|}{1} & \multicolumn{2}{|c|}{2} & \multicolumn{2}{|c|}{3} & \multicolumn{2}{|c|}{4} & \multicolumn{2}{|c|}{5} \\
\hline 1 & 100 & 50.8 & $(-9.3)$ & 128.6 & $(-4.2)$ & 229.0 & $(-15.5)$ & 1007 & $(13.4)$ & 5111 & $(-4.5)$ \\
\hline 2 & 100 & 51.9 & $(-7.3)$ & 122.0 & $(-9.9)$ & 283.0 & (4.4) & 811 & $(-8.8)$ & 4286 & $(-19.9)$ \\
\hline 3 & 200 & 46.8 & $(-16.4)$ & 119.0 & $(-11.3)$ & 217.4 & $(-19.8)$ & 750 & $(-15.5)$ & - & - \\
\hline 4 & 270 & 54.4 & $(-2.9)$ & 131.0 & $(-2.4)$ & 258.6 & $(-4.6)$ & 929 & $(4.6)$ & 4918 & $(-8.1)$ \\
\hline 5 & 270 & 61.2 & $(9.3)$ & 142.9 & $(6.5)$ & 272.7 & $(0.6)$ & 1000 & (12.6) & 3000 & $(-43.9)$ \\
\hline 6 & 270 & 52.6 & $(-6.1)$ & 124.5 & $(-7.2)$ & 252.1 & $(-7.0)$ & 888 & $(0.0)$ & 4770 & $(-10.9)$ \\
\hline 7 & 270 & 57.6 & (2.9) & 151.5 & (12.9) & 329.0 & $(21.4)$ & 1163 & $(31.0)$ & 6667 & $(24.6)$ \\
\hline 8 & 270 & 58.5 & $(4.5)$ & 140.0 & (4.3) & 278.0 & (2.6) & 646 & $(-27.3)$ & 6211 & (16.1) \\
\hline 9 & 270 & 56.6 & (1.1) & 136.4 & (1.6) & 260.9 & $(-3.7)$ & 904 & (1.8) & 4918 & $(-8.1)$ \\
\hline 10 & 270 & 58.3 & (4.1) & 125.5 & $(-6.5)$ & 256.4 & $(-5.4)$ & 974 & (9.7) & 6110 & (14.2) \\
\hline 11 & 270 & 57.6 & (2.9) & 137.0 & $(2.1)$ & 275.2 & (1.5) & 940 & (5.9) & 5848 & (9.3) \\
\hline 12 & 270 & 55.4 & $(-1.1)$ & 132.2 & $(-1.5)$ & 260.9 & (3.7) & 915 & (3.0) & 5445 & (1.7) \\
\hline 13 & 300 & 51.6 & $(-7.9)$ & 120.0 & $(-10.6)$ & 246.0 & $(-9.2)$ & 680 & $(-23.4)$ & 4080 & $(-23.8)$ \\
\hline 14 & 360 & 53.8 & $(-3.9)$ & 128.8 & $(-4.0)$ & 300.0 & (10.7) & 600 & $(-32.4)$ & 3333 & $(-37.7)$ \\
\hline 15 & 400 & 55.4 & $(-1.1)$ & 136.0 & (1.3) & 270.1 & $(-0.3)$ & 924 & (4.1) & 4107 & $(-23.3)$ \\
\hline 16 & 400 & 58.8 & $(5.0)$ & 143.0 & (6.6) & 250.0 & $(-7.7)$ & 750 & $(-15.5)$ & - & - \\
\hline 17 & 400 & 56.1 & $(0.2)$ & 135.0 & $(0.6)$ & 268.0 & $(-1.1)$ & 955 & (7.5) & 5700 & (6.5) \\
\hline 18 & 400 & 59.1 & (5.5) & 139.0 & (3.6) & 286.0 & $(5.5)$ & 739 & $(-16.8)$ & 6464 & (20.8) \\
\hline 19 & 400 & 56.0 & $(0.0)$ & 129.9 & $(-3.2)$ & 263.2 & $(-2.9)$ & 875 & $(-1.5)$ & 5263 & $(-1.7)$ \\
\hline 20 & 400 & 56.6 & (1.1) & 135.1 & $(-0.7)$ & 275.2 & $(1.5)$ & 949 & (6.9) & 6148 & (14.9) \\
\hline 21 & 400 & 54.9 & $(-2.0)$ & 132.0 & $(-1.6)$ & 305.0 & (12.5) & 943 & $(6.2)$ & 7040 & (31.5) \\
\hline 22 & 500 & 51.0 & $(-8.9)$ & 126.7 & $(-5.6)$ & 244.0 & $(-9.9)$ & 843 & $(-5.1)$ & 4815 & $(-10.0)$ \\
\hline 23 & 500 & 56.2 & $(0.4)$ & 133.0 & $(-0.9)$ & 275.0 & (1.5) & 1060 & (19.4) & 6880 & (28.6) \\
\hline 24 & 500 & 56.6 & (1.1) & 132.0 & $(-1.6)$ & 270.0 & $(-0.4)$ & 683 & $(-23.1)$ & 3243 & $(-39.4)$ \\
\hline 25 & 500 & 62.8 & (12.1) & 142.0 & $(5.8)$ & 306.0 & (12.9) & 1070 & $(20.5)$ & - & - \\
\hline 26 & 500 & 60.0 & (7.1) & 160.0 & (19.2) & 301.0 & (11.1) & 974 & (9.7) & 8090 & (51.2) \\
\hline 27 & 500 & 61.0 & (8.9) & 140.2 & $(4.5)$ & 283.0 & (4.4) & 1000 & $(12.6)$ & 6000 & (12.1) \\
\hline \multicolumn{2}{|c|}{ Average } & 56.0 & & 134.2 & & 271.0 & & 888 & & 5352 & \\
\hline \multicolumn{2}{|c|}{ Precision(\%) } & 6.4 & & 6.7 & & 8.9 & & 15.4 & & 23.4 & \\
\hline \multicolumn{2}{|c|}{$D P(\mathrm{SEC})^{\mathrm{b}}$} & 53.4 & & 120.6 & & 256.0 & & 977 & & 5200 & \\
\hline
\end{tabular}

${ }^{\mathrm{a}}$ Figures in parentheses represent the values of $100 \times[$ (an individual determination) $-($ average $)] /($ average $) .{ }^{\mathrm{b}} D P$ determined by SEC.

Table VI. ${ }^{1} \mathrm{H}$ NMR Determination of $D P$ of $i t$-PMMA samples—Data sorted out in terms of frequency of measurement

\begin{tabular}{llllllc}
\hline $\begin{array}{l}\text { Freq. } \\
(\mathrm{MHz})\end{array}$ & $\mathrm{n}^{\mathrm{b}}$ & \multicolumn{5}{c}{ Sample $^{\mathrm{a}}$} \\
\cline { 3 - 7 } & & \multicolumn{1}{c}{1} & \multicolumn{1}{c}{2} & \multicolumn{1}{c}{3} & \multicolumn{1}{c}{5} \\
\hline 100 & 2 & $51.4(1.1)$ & $125(2.6)$ & $256(10.5)$ & $909(10.8)$ & $4699(8.8)$ \\
200 & 1 & $46.8(-)$ & $119(-)$ & $217(-)$ & $750(-)$ & - \\
270 & 9 & $56.9(4.2)$ & $136(5.9)$ & $272(8.2)$ & $928(14.0)$ & $5320(19.3)$ \\
300 & 1 & $51.6(-)$ & $120(-)$ & $246(-)$ & $680(-)$ & $4080(-)$ \\
360 & 1 & $53.8(-)$ & $129(-)$ & $300(-)$ & $600(-)$ & $3330(-)$ \\
400 & 7 & $56.7(2.6)$ & $136(3.0)$ & $274(5.9)$ & $876(9.9)$ & $5790(16.2)$ \\
500 & 6 & $57.7(6.7)$ & $139(7.7)$ & $280(7.4)$ & $938(14.5)$ & $5806(28.8)$ \\
\hline$D P(\text { SEC })^{\mathrm{c}}$ & & 53.4 & 120.6 & 256 & 977 & 5200 \\
$100^{\mathrm{d}}$ & & $52.3(3.9)$ & $122(5.6)$ & $263(8.3)$ & $1020(6.0)$ & $5420(9.2)$ \\
$500^{\mathrm{d}}$ & & $50.5(1.3)$ & $119(3.1)$ & $246(0.9)$ & $912(0.7)$ & $4750(3.4)$ \\
\hline
\end{tabular}

${ }^{a}$ Figures in parentheses represent the precision (\%). ${ }^{\mathrm{b}}$ Number of instruments used. ${ }^{\mathrm{c}}$ Determined by SEC. ${ }^{\mathrm{d} D a t a}$ were collected from the five runs of single spectrometer.

SEC if the experimental errors of both measurements are taken into account.

The fluctuation of the data must be small when the measurements are made at one test site using a single spectrometer. The results of the $D P$ determinations from the single ${ }^{1} \mathrm{H}$ NMR spectrometers (Osaka University) operated at 100 and $500 \mathrm{MHz}$, respectively, are shown in Table VI (the bottom two lines). The precisions remain within $10 \%$ for all the samples even in the data obtained from a $100 \mathrm{MHz}$ spectrometer. Precisions 
for $500 \mathrm{MHz}$ NMR data are less than at most 3.4\%. The averaged $D P$ values for all the samples agreed very well with the $D P$ determined by SEC within the experimental errors. The intensity ratio of the peaks due to the $\mathrm{OCH}_{3}$ protons to $t-\mathrm{C}_{4} \mathrm{H}_{9}-$ group for sample 5 is about 1780:1 on average. The precision and accuracy for the determination of the ratio of this magnitude have been found to be 8.6 and $2.9 \%$ for $100 \mathrm{MHz}$ NMR and 4.3 and $2.9 \%$ for $500 \mathrm{MHz}$ NMR. ${ }^{8}$ Thus, the $D P$ of the polymer having an end group of definite chemical structure can be determined precisely and accurately by ${ }^{1} \mathrm{H}$ NMR up to the $D P$ value at least 5000 . In the present study by round robin method the numbers of scans used for sample 5 were from 32 to 5700 . The maximum value of $D P$ that could be measured by ${ }^{1} \mathrm{H}$ NMR would be increased more if the number of scans would be increased.

The data of $D P$ in Table $\mathrm{V}$ were sorted out based on the frequency of measurements and the results are shown in Table VI. The precision and the agreement of the NMR data with SEC data do not seem to depend strongly on the frequency of measurement although there exists a trend that the values of precision increased with increasing frequency. The same trend for intensity measurement in ${ }^{1} \mathrm{H}$ NMR was observed in our previous work. ${ }^{9}$

The nuclear Overhauser effect (NOE) value of every carbon of PMMA differs from each other, particularly at higher frequency of measurement and removal of NOE should be needed for the accurate determination of peak intensities. ${ }^{2}$ For the purpose, the ${ }^{13} \mathrm{C}$ NMR spectra were measured by gate decoupling without NOE. From the gate-decoupled ${ }^{13} \mathrm{C}$ NMR spectra, the $D P$ values of the samples 1,2 , and 3 were obtained using the signal intensities of methyl carbons of $\alpha-\mathrm{CH}_{3}$ and $t-\mathrm{C}_{4} \mathrm{H}_{9}$ groups and are shown in Table VII by sorting the data in terms of the frequency. $D P$ determinations for samples 4 and 5 are almost impossible in the measurements of 5000 scans (about $14 \mathrm{~h}$ ) due to the low $\mathrm{S} / \mathrm{N}$ ratios of $\mathrm{CH}_{3}$ carbon signal of $t-\mathrm{C}_{4} \mathrm{H}_{9}-$ group. Although the values of precisions for the data shown in Table VII are large as compared with those for the ${ }^{1} \mathrm{H}$ NMR data in Tables V and VI, the averaged values of $D P$ agreed with those obtained by ${ }^{1} \mathrm{H}$ NMR and SEC.

In conclusion the $D P$ of the PMMA having a $t-\mathrm{C}_{4} \mathrm{H}_{9}-$ group at the chain end can be determined accurately
Table VII. ${ }^{13} \mathrm{C}$ NMR Determination of $D P$ of $i t$-PMMA samples $^{\mathrm{a}}$

\begin{tabular}{cllllll}
\hline \multirow{2}{*}{$\begin{array}{c}\text { Freq. } \\
(\mathrm{MHz})\end{array}$} & \multicolumn{2}{c}{ Sample 1 } & \multicolumn{2}{c}{ Sample 2 } & \multicolumn{2}{c}{ Sample 3 } \\
\cline { 2 - 7 } & \multicolumn{1}{c}{$\mathrm{n}^{\mathrm{b}}$} & \multicolumn{1}{c}{$D P$} & $\mathrm{n}^{\mathrm{b}}$ & $D P$ & $\mathrm{n}^{\mathrm{b}}$ \\
\hline 50 & $60.6(-)$ & 1 & - & & - & \\
67.5 & $48.3(16.1)$ & 9 & $123(20.6)$ & 8 & $285(16.9)$ & 6 \\
75 & $62.1(-)$ & 1 & $116(-)$ & 1 & - & \\
90.6 & $60.5(-)$ & 1 & $169(-)$ & 1 & - & \\
100 & $54.6(11.1)$ & 4 & $128(8.5)$ & 4 & $240(9.5)$ & 2 \\
125 & $48.5(5.7)$ & 4 & $128(16.1)$ & 4 & $262(0.4)$ & 2 \\
\hdashline Ave. & $51.5(14.8)$ & 20 & $126(18.3)$ & 18 & $271(15.8)$ & 10 \\
\hline
\end{tabular}

${ }^{\mathrm{a}}$ Figures in parentheses represent the precision (\%). ${ }^{\mathrm{b}}$ Number of spectrometers.

and precisely by ${ }^{1} \mathrm{H}$ NMR spectroscopy up to the $D P$ of about 5000 in the measurements with $32-5700$ scans and repetition time of $10 \mathrm{~s}$. In the case of ${ }^{13} \mathrm{C}$ NMR the maximum value of $D P$ that can be measured practically is around 300.

Acknowledgment. The authors are grateful to Professor R. Chujo of The Nishi-Tokyo-University and Professor I. Ando of Tokyo Institute of Technology for helpful discussions and to Dr. N. Fujimoto of Sumitomo Seika Chemicals Co., LTD. for the preparation of the it-PMMA samples.

\section{REFERENCES}

1. R. Chujo, K. Hatada, R. Kitamaru, T. Kitayama, H. Sato, and Y. Tanaka, Polym. J., 19, 413 (1987).

2. R. Chujo, K. Hatada, R. Kitamaru, H. Sato, Y. Tanaka, F. Horii, and Y. Terawaki, Polym. J., 20, 627 (1988).

3. F. Horii, M. Nakagawa, R. Kitamaru, R. Chujo, K. Hatada, and Y. Tanaka, Polym. J., 24, 1155 (1992).

4. K. Hatada, T. Kitayama, Y. Terawaki, H. Sato, R. Chujo, Y. Tanaka, R. Kitamaru, I. Ando, K. Hikichi, and F. Horii, Polym. J., 27, 1104 (1995).

5. The Committee on Molecular Weight and Molecular Weight Distribution of the Society of Polymer Science, Japan, Rep. Prog. Polym. Phys. Jpn., 7, Suppl., 5 (1964).

6. K. Hatada, K. Ute, K. Tanaka, Y. Okamoto, and T. Kitayama, Polym. J., 18, 1037 (1986).

7. J. Demarquay, P. Q. Tho, M. Guyot de la Hardrouyere, A. Guyot, and M. Prettre, C. R. Acad. Sci. Paris, 259, 3509 (1964).

8. K. Hatada, T. Kitayama, and Y. Terawaki, unpublished results.

9. K. Hatada, T. Kitayama, K. Ute, and Y. Terawaki, unpublished results. 